OPEN ACCESS

Edited by:

Miguel Ferrer,

Spanish National Research Council (CSIC), Spain

Reviewed by:

Phuntsho Thinley,

University of New England, Australia

Richard Patrick Reading,

Butterfly Pavilion, United States

${ }^{*}$ Correspondence:

J. David Wiens

jwiens@usgs.gov

Specialty section:

This article was submitted to

Conservation and Restoration

Ecology,

a section of the journal

Frontiers in Ecology and Evolution

Received: 08 February 2021

Accepted: 09 December 2021

Published: 21 January 2022

Citation:

Wiens JD, Bloom PH,

Madden MC, Kolar PS, Tracey JA and

Fisher RN (2022) Golden Eagle

Occupancy Surveys and Monitoring

Strategy in Coastal Southern

California, United States.

Front. Ecol. Evol. 9:665792.

doi: 10.3389/fevo.2021.665792

\section{Golden Eagle Occupancy Surveys and Monitoring Strategy in Coastal Southern California, United States}

\author{
J. David Wiens ${ }^{1 *}$, Peter H. Bloom ${ }^{2}$, Melanie C. Madden ${ }^{3}$, Patrick S. Kolar', \\ Jeff A. Tracey ${ }^{3}$ and Robert N. Fisher ${ }^{3}$
}

1 U.S. Geological Survey, Forest and Rangeland Ecosystem Science Center, Corvallis, OR, United States, ${ }^{2}$ Bloom Research Inc., Santa Ana, CA, United States, ${ }^{3}$ U.S. Geological Survey, Western Ecological Research Center, San Diego, CA,

United States

Golden eagles (Aquila chrysaetos) are of increasing conservation concern in western North America. Effective conservation measures for this wide-ranging, federally protected raptor species require monitoring frameworks that accommodate strong inference on the status of breeding populations across vast landscapes. We used a broad-scale sampling design to identify relationships between landscape conditions, detection rates, and site occupancy by territorial pairs of golden eagles in coastal southern California, United States. In 2016 and 2017, we surveyed 175 territory-sized sample sites (13.9- $\mathrm{km}^{2}$ randomly selected grid cells) up to four times each year and detected a pair of eagles at least once in $22(12.6 \%)$ sites. The probability of detecting pairs of eagles varied substantially between years and declined with increasing amounts of forest cover at survey sites, which obscured observations of eagles during groundbased surveys. After accounting for variable detection, the mean estimate of expected site occupancy by eagle pairs was 0.156 (SE $=0.081)$. Site-level estimates of occupancy were greatest $(>0.30)$ at sample sites with more rugged terrain conditions, $<20 \%$ human development, and lower amounts of scrubland vegetation cover. The proportion of a sample site with open grassland or forest cover was not strongly correlated with occupancy. We estimated that approximately $16 \%$ of the $5,338-\mathrm{km}^{2}$ sampling frame was used by resident pairs of golden eagles, corresponding to a sparsely distributed population of about 60 pairs ( $95 \% \mathrm{Cl}=19-151$ pairs). Our study provided baseline data for future surveys of golden eagles along with a widely applicable monitoring framework for identifying spatial conservation priorities in urbanizing landscapes.

Keywords: California birds, detection probability, golden eagle, Aquila chrysaetos, N-mixture model, occupancy model

\section{INTRODUCTION}

Human alteration of landscapes is recognized as a primary threat to the persistence of raptors throughout the world (McClure et al., 2018). Their high trophic level and associated role in structuring biological communities has made raptors an important consideration for large-scale, ecosystem-based management strategies (e.g., Reynolds et al., 1992; Lesmeister et al., 2018). 
Identifying how human land use and other landscape characteristics shape the distribution of wide-ranging apex predators is, therefore, a key step toward biodiversity conservation (Sergio et al., 2006; Lawler et al., 2008; Hole et al., 2011). In birds of prey, human land-use activities and associated disturbances can fragment and degrade nesting and foraging habitats, increase mortality rates, and reduce reproductive success and territory occupancy (White et al., 2018; Cooper et al., 2020). Wide-ranging raptor species are especially susceptible to the cumulative impacts of humancaused disturbances because localized stressors can translate to broader impacts on highly interconnected populations (e.g., Katzner et al., 2017). The ability to manage or offset these negative impacts requires a deeper understanding of interactions between landscape features and the population characteristics of a species. Broad-scale survey designs are needed to identify possible population-level responses of rare and highly mobile raptor species to site-level changes in landscape conditions and to inform future management decisions. In this sense, monitoring and survey protocols that are standardized across temporal and spatial scales are essential in establishing linkages between small-scale, short-term conservation efforts and long-term population trajectories (Hewitt et al., 2007; Pavlacky et al., 2017; Wiens et al., 2018).

Golden eagles (Aquila chrysaetos) are among the largest and most wide-ranging avian predators in the world. As such, this species plays a key role in biodiversity functions across vast landscapes and is generally considered an indicator of ecosystem health (Katzner et al., 2020). Recent assessments indicate golden eagle populations in the western U.S. are stable or slightly decreasing, but that projected increases in energy development and land-use change could trigger population declines (Millsap et al., 2013; Nielson et al., 2014; U. S. Fish and Wildlife Service [USFWS], 2016; Hunt et al., 2017). Increasing levels of human land use in areas occupied by golden eagles poses a unique conservation challenge because of this species' sensitivity to expanding human development and recreational activities (Martin et al., 2009; Steenhof et al., 2014; Spaul and Heath, 2016). Potential risks to golden eagles from increasing development and recreational activities are largely indirect, occurring through disturbances to nest sites, loss of foraging habitat and prey availability, or via exposure to contaminants (Bloom et al., 1989; Spaul and Heath, 2016; Herring et al., 2017). Roads, power lines, and wind-energy sites can result in substantial mortality to eagles via collisions, electrocutions on power poles, or direct persecution (Whitfield et al., 2004; Lovich, 2015; Hunt et al., 2017). Recent increases in wildfire frequency and extent may also result in loss and alteration of grassland and forested habitats used for foraging and nesting. In areas where golden eagles are faced with multiple interacting threats associated with intensifying urbanization or landscape disturbance, data are needed on the occurrence and abundance of territorial pairs for long-term monitoring and spatial conservation planning. Continental-wide monitoring programs that use aerial surveys to detect golden eagles have offered important insights into general population trends (e.g., Nielson et al., 2014). These surveys do not distinguish between territorial and non-territorial population segments, however, so have limited utility for regulatory needs or management actions associated with locations of territorial pairs of eagles and their nests.

The field of occupancy estimation and modeling (MacKenzie et al., 2006) provides a rigorous and repeatable framework for monitoring the status of wide-ranging terrestrial wildlife species like golden eagles. Occupancy-based studies focused on monitoring sites (e.g., a territory or other predefined area) have been increasingly used to examine the population dynamics of golden eagles and to evaluate how landscape features or human land use might influence those dynamics (Martin et al., 2009; Stahlecker et al., 2017; Wiens et al., 2018; Tack et al., 2020; Watson et al., 2020). A common strength of these studies is that they accommodate imperfect detection of golden eagles during surveys, which, if not accounted for, can lead to inaccurate inferences about site-use, population status, distribution, or nesting success. Studies of site occupancy also provide a standardized framework for identifying spatial relationships between the presence of a given species and site-specific physiographic conditions. When coupled with a randomized sampling design, occupancy-based studies can also provide a means of predicting occupancy at sites that have not been surveyed (Wiens et al., 2015, 2018; Lukacs et al., 2020), thereby increasing the efficiency and spatial scope of a given wildlife monitoring program.

We implemented a broad-scale, site occupancy-based survey and monitoring strategy to investigate factors affecting the presence of territorial pairs of golden eagles in coastal southern California, United States, during 2016 and 2017. Our primary objectives were to implement a repeatable sampling framework for monitoring golden eagles within the region of interest during the breeding season, and to use that framework to establish an estimate of the occurrence and distribution of territorial pairs of golden eagles. We also wanted to examine several predictions concerning how heterogeneous landscape conditions in our study area may influence the detectability and occurrence of eagle pairs. First, we predicted that the amount of forest cover at survey sites negatively affected an observer's ability to detect pairs of eagles under the ground-based survey protocols we used (Wiens et al., 2015). Second, we anticipated that site occupancy by territorial pairs of golden eagles would be positively associated with rugged, open landscapes because prey-detection, hunting success, and nesting locations are most often associated with these conditions (Marzluff et al., 1997; Singh et al., 2016; Dunk et al., 2019; Katzner et al., 2020). Based on these previous findings, and the results of a site-occupancy study in westcentral California (Wiens et al., 2015, 2018), we predicted that occupancy of golden eagle pairs would be positively associated with open (grassland) landscapes with increasingly rugged terrain conditions, but negatively associated with dense chaparral scrubland. Finally, we predicted that site occupancy of eagles would be lower at sites with relatively more human development (Scott, 1985; Tracey et al., 2018a). We then demonstrate how the monitoring design may be used to estimate and map the spatial distribution of sites most likely to be used by territorial pairs of golden eagles, which should be useful for supporting 
local conservation priorities or management decisions for this federally protected species.

\section{MATERIALS AND METHODS}

\section{Study Area and Eagle Population}

Our study was conducted during 2016 and 2017 in the mountains, foothills, canyons, and valleys of the coastal and transmontane region of southern California, United States (Figure 1). The focal $5,338-\mathrm{km}^{2}$ study area spanned from the Pacific coast to mountains $>1,200 \mathrm{~m}$ in elevation and encompassed a range of ecosystem types, including coastal sage scrub and chaparral, grasslands, oak woodlands, and coniferous forests (Farley et al., 2017). The region was characterized by Mediterranean-type climate with a high degree of year-to-year and within-year precipitation variability, strong seasonality, and low-level coastal clouds (Clemesha et al., 2016). The coastal section of our study area was densely populated with people in urbanized landscapes extending into interior valleys west of the coast range. Over the past 80 years, much of the study region was transformed from mostly rural, ranching landscapes with grassland and scattered oaks, to a landscape with large expanses of homes and businesses interspersed with protected open space (Gillespie et al., 2012). Intensive urbanization of coastal southern California has eliminated much of the native sage-scrub vegetation cover, leaving undeveloped steep-sided canyons and protected areas as habitat islands in an urban sea (Crooks and Soulé, 1999). Habitat loss and fragmentation are of mounting concern for biodiversity conservation given the region's high levels of population growth, increasing urbanization, and pressure to develop land (Syphard et al., 2011; Farley et al., 2017; Tracey et al., 2018b).

Coastal southern California has a rich history of ornithological investigation dating back to the 1800's (Grinnell, 1898). Historical (pre-1900) records of golden eagles and their nests were primarily made by egg collectors. More detailed observations of territorial pairs of eagles in northwestern San Diego County were first documented in the early 1900's (Dixon, 1937) but not again until the early 1980's (Scott, 1985). Surveys completed in the later study indicated that many of the golden eagle territories first described by Dixon (1937) had been abandoned as a result of development and increasing urbanization, resulting in local population declines as severe as 60\% (Scott, 1985). Golden eagles in coastal southern California historically used closed canopy coast live oak (Quercus agrifolia) woodland and grassland savannahs in the lowlands, while often nesting in coast live oak and canyon live oak (Quercus chrysolepis) forests in the uplands, or occasionally in western sycamores (Platanus racemosa) and non-native eucalyptus (Eucalyptus spp.) trees. With increasing urbanization, golden eagles may be increasingly restricted to cliff-side nests in more rugged, inland landscapes of southern California, including deserts to the east (Brown, 2014). Resident birds, non-territorial individuals (i.e., floaters and
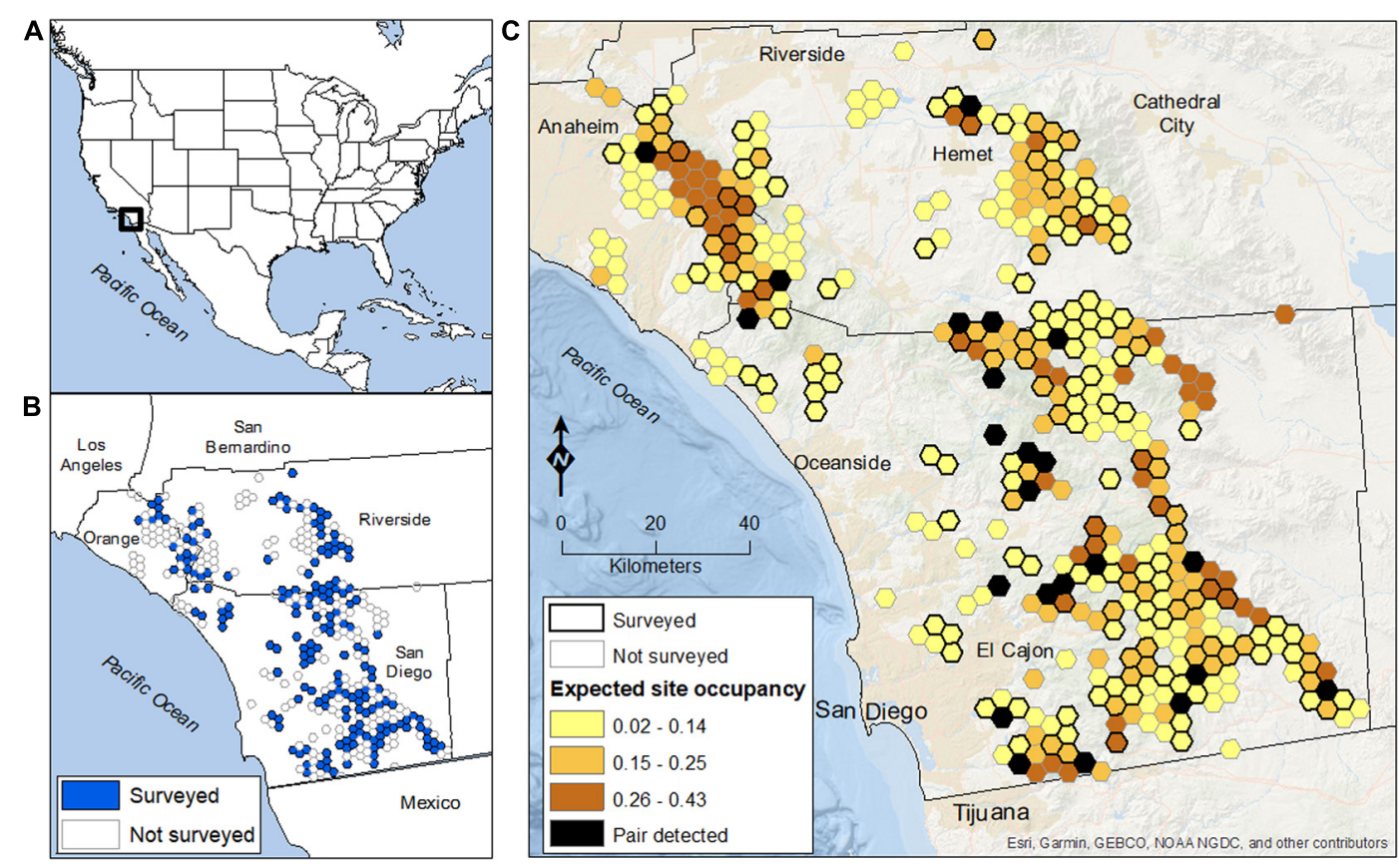

FIGURE 1 | The golden eagle study area, sampling grid, and expected estimates of site occupancy in coastal southern California, United States. (A) Location of the study region in the western U.S. (B) Extent of the sampling grid of $13.9 \mathrm{~km}^{2}$ hexagon sites $(n=384)$, including 175 randomly selected sites (blue hexagons) that were repeatedly surveyed for eagles in 2016 and 2017. (C) Spatial distribution of model-averaged values of expected site occupancy for territorial pairs of golden eagles. Black hexagons indicate sites where a pair of eagles was detected at least once (i.e., $\psi_{\text {conditional }}=1.0$ ). Mean expected occupancy across the 5,338 -km ${ }^{2}$ sampling frame was 0.156 (SE $=0.081$ ), indicating that approximately $833 \mathrm{~km}^{2}$ of the $5,338-\mathrm{km}^{2}$ study area was used by resident pairs of eagles (equivalent to about 60 occupied sites). 
younger age-classes), and migratory eagles all use the region in winter (Tracey et al., 2018a, 2020).

\section{Sampling Design and Survey Protocol}

Our sampling design and field protocols replicated those used to monitor a large, tree-nesting population of golden eagles in west-central California (Wiens et al., 2015, 2018, 2020). As such, areas targeted for surveys were randomly selected from a grid of equal-sized $\left(13.9 \mathrm{~km}^{2}\right)$ hexagonal sample cells overlaid across the region of interest (Figure 1B). The size of each survey hexagon approximated the mean territory size of golden eagles (Wiens et al., 2015). Thus, under our sampling design a "site" was defined as a territory-sized hexagonal cell that had the potential to be occupied by at least one territorial pair of golden eagles during the breeding season (January - July). Our focal interest was in characterizing distribution and abundance of eagles across the matrix of publicly owned lands and designated protected areas of western San Diego and Riverside Counties, in addition to eastern Orange County (Figure 1B). Accordingly, a hexagon was considered available for random selection if it was comprised of $\geq 50 \%$ publicly owned and $\leq 50 \%$ developed land ( $n=384$ eligible hexagons in the sample frame). We focused on this subset of sites to facilitate access during field surveys, but also because these lands were more likely to remain protected and be managed to maintain golden eagles over the long-term. We used program GENPRES to evaluate design trade-offs between the number of sites monitored and number of surveys to each site (Bailey et al., 2007). Based on the results, we randomly selected 175 of the 384 eligible hexagons to receive 4 visits each per year. Thus, we randomly sampled and surveyed approximately $2,433-\mathrm{km}^{2}$ (46\%) of the $5,338-\mathrm{km}^{2}$ sampling frame. An important element of this survey design was that all sample units (hexagons) in the sampling frame were equally available for selection, which permitted statistical inference to the entire focal population within the sample frame, including sites not surveyed (Thompson et al., 1998; Wiens et al., 2015; Lukacs et al., 2020).

We partitioned surveys within seasons based on approximate transition dates for stages in the breeding cycle of golden eagles in the study region: courtship (15 December-28 February), incubation (1 March-30 April), nestling (1 May-15 June), and the fledging-dependency period (16 June-30 July). During each survey, observers established ground-based observation points on ridges or hilltops that provided views of the focal sample site. Observers then searched for evidence of occupancy by golden eagles within the site for up to 4-h per survey using binoculars and spotting scopes (Wiens et al., 2015, 2018). A sample site was considered to be used by a territorial pair of eagles if we observed: (1) a male and female copulating, undulating, perching together, or attacking intruders; or (2) an incubating eagle in a nest, young in a nest, or a female with a brood patch. We attributed detections of territorial pairs to sample sites by mapping activity centers of pair observations, defined by a used nest, locations of fledglings with adults, or a focal area of copulations, territorial displays, and pairs perching together (Wiens et al., 2015, 2018). Detections of eagle pairs with activity centers outside of focal sample sites were recorded, but not included in analyses of occupancy.

\section{Landscape Conditions}

We used the National Oceanic and Atmospheric Administration's Coastal Change Analysis Program (C-CAP) regional land cover map (NOAA, 2010) to characterize primary vegetation types and developed areas in the study region. This was the same map used in previous applications of the survey design (Wiens et al., 2015, 2018), which facilitated comparisons of results between the two different California study areas. The C-CAP map included 29 categories of land cover (21 of which occurred within our study area) and was produced using 30-m resolution Landsat Thematic Mapper and Landsat Enhanced Thematic Mapper satellite imagery (NOAA, 2010). We combined existing land-cover types into four general categories (developed areas, open grassland, scrub and shrub vegetation, and forest cover) and calculated their proportion in each $13.9 \mathrm{~km}^{2}$ sample site (Table $\mathbf{1}$ ).

Landscape topography interacts with wind to promote flight behaviors, hunting tactics, and habitat use by golden eagles (McLeod et al., 2002; Katzner et al., 2012; Wiens et al., 2018; Sur et al., 2020). We explored associations between terrain conditions and site occupancy of eagles using the $30-\mathrm{m}$ resolution National Elevation Dataset DEM (U. S. Geological Survey [USGS], 2015) to calculate a mean terrain ruggedness index (TRI; Riley et al., 1999) for each sample site in our study area. We calculated mean

TABLE 1 | Landscape covariates used to characterize spatial variation in site occupancy of territorial pairs of Golden Eagles in coastal southern California, United States, $2016-2017$.

\begin{tabular}{|c|c|c|}
\hline Covariate & Description & Mean value (SD, $\min -\max )^{b}$ \\
\hline Developed ${ }^{\mathrm{a}}$ & $\begin{array}{l}\text { Low-, medium-, and high-intensity development, roads, constructed surfaces, and associated trees } \\
\text { and grasses (NOAA, 2010). }\end{array}$ & $0.03(0.08,0.00-0.46)$ \\
\hline Grassland $^{\mathrm{a}}$ & Graminoid or herbaceous vegetation, generally greater than $80 \%$ of total vegetation (NOAA, 2010). & $0.14(0.16,0.00-0.94)$ \\
\hline Scrubland ${ }^{a}$ & $\begin{array}{l}\text { Shrubs less than } 5 \text {-m tall with shrub canopy }>20 \% \text { of total vegetation cover. Included tree shrubs } \\
\text { and young trees in early successional stage (NOAA, 2010). }\end{array}$ & $0.70(0.23,0.02-0.99)$ \\
\hline Forest $^{\mathrm{a}}$ & $\begin{array}{l}\text { Trees generally }>5-m \text { tall and }>20 \% \text { of total vegetation cover. Included deciduous, evergreen and } \\
\text { mixed coniferous species (NOAA, 2010). }\end{array}$ & $0.11(0.19,0.00-0.89)$ \\
\hline Terrain ruggedness (TRI) & $\begin{array}{l}\text { A measure of terrain heterogeneity, where larger values indicate greater heterogeneity, or more rugged } \\
\text { areas (Riley et al., 1999; Evans et al., 2014). }\end{array}$ & $4.09(2.50,0.06-12.07)$ \\
\hline
\end{tabular}

${ }^{a}$ Calculated as the proportion within survey sites (13.9 $\mathrm{km}^{2}$ hexagons).

${ }^{b}$ Calculated using the sample of sites surveyed $(n=175)$. 
values of TRI for each site as the square root of the sum of the squared differences between the elevation in a 30-m cell and the elevation of its neighboring cells using the Geomorphometric and Gradient Metrics Toolbox in ArcGIS 10.3 (Evans et al., 2014; Sur et al., 2020). We considered mean values as a measure of relative terrain heterogeneity among sites, where larger values indicated greater heterogeneity, or a more rugged area.

\section{Modeling Site Occupancy of Territorial Pairs}

We used a multi-season occupancy model (MacKenzie et al., 2003) to estimate site occupancy and detection rates of territorial pairs of golden eagles. The model allowed us to estimate (1) $\psi_{t}$, the probability that a site is occupied by at least one pair of golden eagles in year $t$; (2) $p_{i, t}$, the probability of detecting at least one pair of eagles given that one is present on survey $i$ of year $t$; (3) $\gamma_{t}$, the probability that an unoccupied site in year $t$ will be occupied in year $t+1$ (local colonization); and (4) $\varepsilon_{t}$, the probability that an occupied site in year $t$ will be unoccupied in year $t+1$ (local extinction). We used this analytical framework because it correctly accounted for dependency between years in the occupancy status of repeatedly surveyed sample sites. The approach assumed that (1) there was within-site closure during repeated surveys within the breeding season; and (2) detection histories among sample sites were independent. The study design and field protocols we used minimized the risk of violating these assumptions, but our sample sites (i.e., randomly placed hexagons) were not centered on actual territory locations or home ranges of golden eagles. Accordingly, we considered our occupancy response variable $(\psi)$ to reflect "site-use" by territorial pairs of eagles (MacKenzie, 2005; MacKenzie et al., 2006), and $p$ as the joint probability that a pair of eagles was both available and detected during a given survey occasion. We retain the term "occupancy" to maintain standard terminology used for this modeling approach. We assessed goodness of fit for occupancy models using simulation methods and the Pearson chi-square test statistic (MacKenzie and Bailey, 2004; Fiske and Chandler, 2011). Specifically, we bootstrapped model estimates 1,000 times to obtain $P$-values of model fit and to estimate a dispersion parameter $(\hat{c})$ as the ratio of the observed chi-square statistic to the mean of the simulated distribution (Burnham and Anderson, 2002).

We used a secondary candidate set model building strategy (Morin et al., 2020) to explore how landscape conditions may have affected the presence of eagle pairs in our sample sites. The strategy entailed ranking a separate candidate set of submodels for $\psi$ and $p$ first, then combining the best supported models from each sub-model set to attain a final candidate set of models. Given the short duration of our study (2 years), we treated turnover rates in occupancy status between years $(\varepsilon, \gamma)$ as constant (.) and focused model development on $\psi$ and $p$. We initially ranked 8 competitive models for $p$ and 10 models for $\psi$, including null (intercept-only) models for comparisons (Supplementary Table 1). We fixed $p$ to a general time-varying model (year) when evaluating sub-models for $\psi$, and we treated $\psi$ as constant (.) when evaluating submodels for $p$. Each candidate model represented a different hypothesis about factors affecting site occupancy or detection rates of golden eagles. In competing models for $p$ we allowed detection to be constant, vary between primary sampling periods (years), vary among secondary sampling periods (i.e., stages of the breeding cycle within years), or to vary both within and between years. We also explored associations between detection and the proportion of a survey site with forest cover, which may negatively affect an observer's ability to detect pairs of eagles under the survey protocol we used (Wiens et al., 2015). Initial competing models for $\psi$ included univariate effects of 5 different landscape covariates (Table 1). Correlation between pairs of landscape covariates was low (all Pearson's $r<0.51$ ), so we considered biologically relevant, additive combinations of relevant landscape covariates in the final candidate set of models. We ranked and evaluated all models using information-theoretic methods and Akaike Information Criterion values adjusted for small sample size $\left(\mathrm{AIC}_{c}\right.$; Burnham and Anderson, 2002). We considered models within $4 \mathrm{AIC}_{c}$ units of the top-ranked model to have some support and those within $2 \mathrm{AIC}_{c}$ units to have substantial support from the data (Burnham and Anderson, 2002). Thus, we combined all sub-models from the initial stage of the analysis that were within $4 \mathrm{AIC}_{c}$ units of the lowest $\mathrm{AIC}_{c}$ model, resulting in a final set of 44 candidate models for $\psi$ and $p$ (Supplementary Table 1).

We used the final candidate set of models to calculate modelaveraged estimates (and unconditional standard errors) of all model parameters (Burnham and Anderson, 2002). We then calculated the model-averaged probability of site occupancy for each of the 384 sites in the sampling frame using known covariate values for each site and fixing $\psi=1$ for sites with at least one detection (MacKenzie et al., 2006; Wiens et al., 2015, 2018; Lukacs et al., 2020). We estimated the expected total number of sites used by territorial pairs of eagles as the sum of site-specific, modelaveraged estimates of occupancy divided by the total number of sites in the sampling frame $(n=384$; Rich et al., 2013; Wiens et al., 2015; Black et al., 2019). Given that our sampling units approximated the mean size of a single golden eagle territory, we believe the expected number of sites used was a reasonable approximation of abundance of territorial pairs. For comparison with modeled estimates, we calculated naïve abundance of golden eagle pairs using the sum of maximum counts of pair detections across the 175 sites surveyed (Bibby et al., 2000; Chandler et al., 2011; Wiens et al., 2020). We used the "unmarked" (Fiske and Chandler, 2011) and "AICcmodavg” (Mazerolle, 2020) packages in $\mathrm{R}$ version 3.5.1 ( $\mathrm{R}$ Core Team, 2020) for these analyses.

\section{RESULTS}

In 2016 and 2017, we surveyed 175 sample sites up to four times each year (mean $=3.6$ surveys per site per year) and detected a territorial pair of golden eagles on 53 (4\%) of 1,252 survey occasions. We detected pairs of eagles at 14 sites (8\%) in 2016 and at 19 sites (11\%) in 2017. We detected a pair of eagles at least once at $22(13 \%)$ of the 175 sites surveyed in both years of the 
study. We had no observations of $>1$ pair of eagles using the same sample site on the same survey occasion.

We found no evidence of lack of fit for the most generalized occupancy model $\left(\chi^{2}=116.7, P=0.241, \hat{c}=0.690\right)$, indicating adequate model fit to the survey data and model assumptions. Model-averaged estimates of the probability of detection $(\widehat{\bar{p}})$ increased from $0.21(95 \% \mathrm{CI}=0.11-0.35)$ in 2016 to $0.75(95 \%$ $\mathrm{CI}=0.37-0.93$ ) in 2017 (a $71 \%$ increase between years). All models with a $\Delta \mathrm{AIC}_{c} \leq 4$ in the final candidate set of 44 models included the effects of year and forest cover on $p$ (Supplementary Table 1). The probability of detecting pairs of eagles that were present was negatively related to the amount of forest cover at survey sites $(\widehat{\beta}=-4.33, \mathrm{SE}=2.23$; Figure 1A). Models that assumed: (1) constant detection over time; or (2) changes in detection over the course of the breeding season, were not well supported by the data and analysis (Supplementary Table 1).

The model-averaged estimate of site occupancy $(\widehat{\bar{\Psi}})$ was 0.16 (unconditional 95\% CI $=0.02-0.64$ ). All models with $\Delta \mathrm{AIC}_{c} \leq 4$ in the final set of candidate models included the effects of terrain ruggedness (TRI), developed land cover, or scrubland vegetation cover on the estimated probability of site occupancy (Supplementary Table 1). Model-averaged estimates of expected occupancy were greatest at sites with intermediate to high levels of terrain ruggedness, $<20 \%$ developed land cover, and intermediate proportions of scrubland vegetation cover (Figure 2). The overall top model $\left(\Delta \mathrm{AIC}_{c}=0.00\right)$ indicated that site occupancy had a non-linear, quadratic relationship with mean terrain ruggedness (Table 2). Mean expected occupancy estimated the top model was 0.16 in 2016 (bootstrap 95\% CI $=0.07-0.25$ ) and 0.13 in 2017 (bootstrap $95 \% \mathrm{CI}=0.06-0.20)$. Bootstrapped $95 \%$ confidence intervals of annual estimates of occupancy broadly overlapped, indicating little evidence of a difference between years in occupancy. A closely competing model $\left(\Delta \mathrm{AIC}_{c}=0.13\right)$ indicated a positive relationship between terrain ruggedness and occupancy $\widehat{(\beta}$ $=0.34, \mathrm{SE}=0.14)$, a negative relationship between occupancy and the developed land cover $(\widehat{\beta}=-10.31, \mathrm{SE}=7.16)$, and a non-linear (quadratic) effect of scrubland vegetation cover $\left(\widehat{\beta}_{\text {scrub }}=16.46, \mathrm{SE}=11.24 ; \widehat{\beta}_{\text {scrub }}{ }^{2}=-14.66, \mathrm{SE}=8.65\right)$. The proportion of a site with forest or grassland cover types was not strongly correlated with occupancy (Table 2). Model-averaged estimates indicated that the probability that an unoccupied site would be occupied in $2017(\widehat{\gamma})$ was essentially zero $(<0.01, \mathrm{SE}=0.01)$, whereas the probability that an occupied site would become unoccupied $\widehat{(\bar{\varepsilon})}$ was 0.17 (95\% $\mathrm{CI}=0.02-0.98)$.
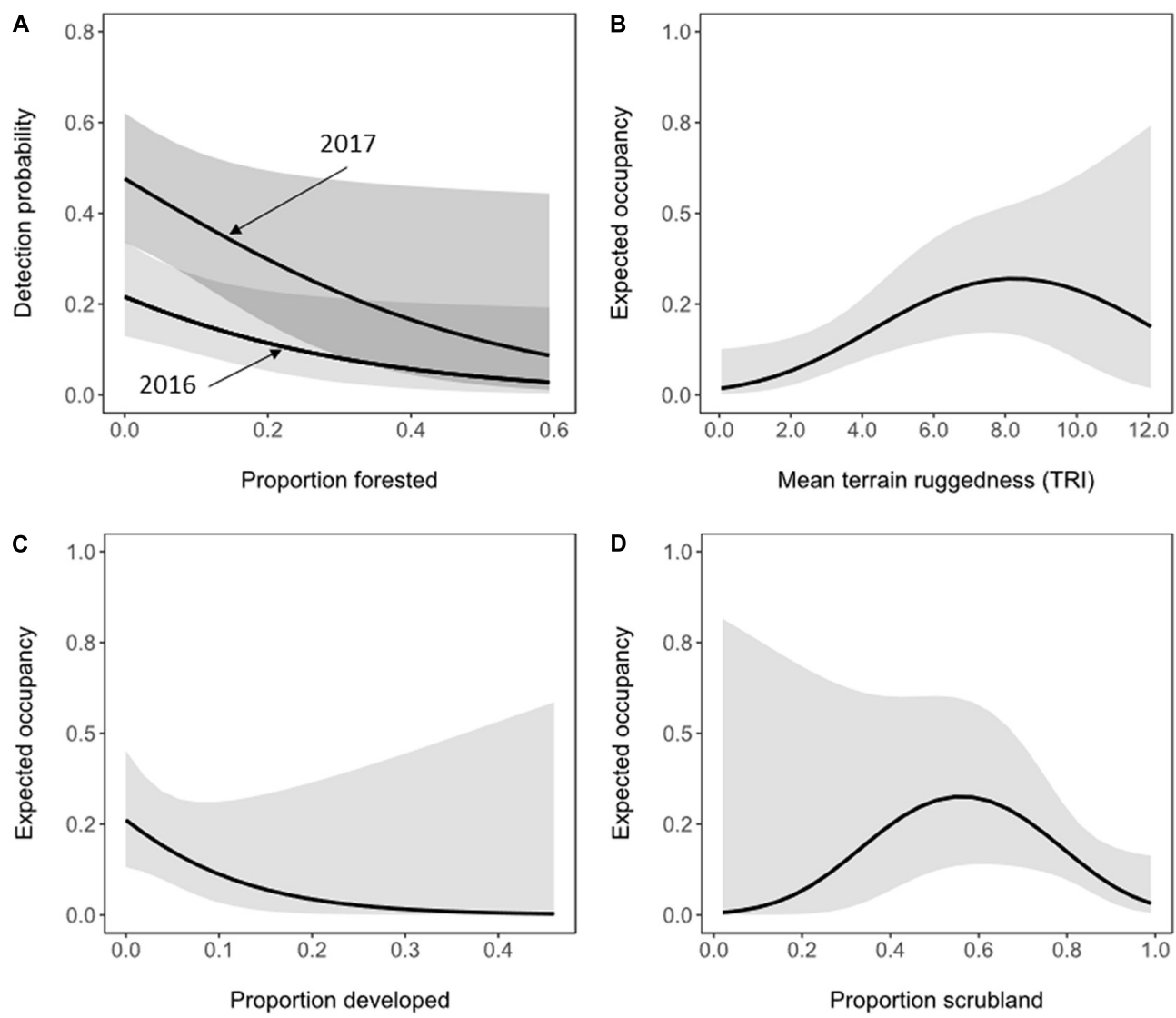

FIGURE 2 | Influence of landscape composition on the probability of detection (A) and expected site occupancy (B-D) of territorial pairs of golden eagles in coastal southern California, United States, 2016 - 2017. Solid lines represent estimates from the best model containing each landscape covariate while holding all other covariates in the model at median values. Shading represents $95 \%$ confidence intervals. 
TABLE 2 | Best model containing the effect of each landscape covariate on site occupancy $(\psi)$ of territorial pairs of golden eagles in coastal southern California, United States, $2016-2017$.

\begin{tabular}{|c|c|c|c|c|c|c|c|}
\hline Covariate & Best model & $\Delta \mathrm{AlC}_{c}$ & Effect & $\widehat{\beta}$ & SE & LCL & UCL \\
\hline \multirow[t]{2}{*}{ Grassland } & $\psi\left(\right.$ grass + grass $\left.^{2}\right) \gamma(.) \varepsilon() p.($ year $)$ & 4.85 & grass & 6.770 & 4.634 & 0.097 & 13.440 \\
\hline & & & grass $^{2}$ & -10.960 & 8.870 & -23.730 & 1.180 \\
\hline \multirow[t]{2}{*}{ Scrubland } & $\psi\left(\right.$ TRI + developed + scrub + scrub $\left.^{2}\right) \gamma(.) \varepsilon() p.($ year + forest $)$ & 0.13 & scrub & 16.464 & 11.242 & -5.570 & 38.497 \\
\hline & & & scrub $^{2}$ & -14.657 & 8.653 & -31.616 & 2.303 \\
\hline Developed & $\psi\left(\mathrm{TRI}+\right.$ developed + scrub + scrub $\left.^{2}\right) \gamma(.) \varepsilon() p.($ year + forest $)$ & 0.13 & developed & -10.306 & 7.160 & -20.613 & 0.000 \\
\hline Forest & $\psi($ forest $) \gamma(.) \varepsilon() p.($ year $)$ & 4.14 & forest & -1.570 & 1.704 & -4.023 & 0.883 \\
\hline \multirow[t]{2}{*}{ Terrain ruggedness index (TRI) } & $\psi\left(\mathrm{TRI}+\mathrm{TR}^{2}\right) \gamma(.) \varepsilon() p.($ year + forest $)$ & 0.00 & $\mathrm{TRI}$ & 8.004 & 0.369 & 2.303 & 13.705 \\
\hline & & & $\left.\mathrm{TR}\right|^{2}$ & -0.485 & 0.032 & -0.952 & -0.010 \\
\hline
\end{tabular}

Model covariate coefficients ( $\widehat{\beta})$, standard errors (SE), and lower (LCL) and upper (UCL) 85\% confidence limits are included for the specified covariate effect in each model.

Mapped, site-specific estimates of $\widehat{\Psi}$ illustrated the spatial distribution of sites with the greatest likelihood of use by territorial pairs of eagles (Figure 1C). Contiguous areas of relatively greater expected occupancy were located primarily in the northwest section of the study area, or in more remote areas along the eastern edge of the sampling grid. The average probability of occupancy across all 384 sites was 0.156 $(\mathrm{SE}=0.081)$, indicating that approximately $833 \mathrm{~km}^{2}$ of the $5,338 \mathrm{~km}^{2}$ sampling frame was used by territorial pairs of eagles during the study. Assuming a mean territory size among pairs equivalent to the size of each sample site $\left(13.9 \mathrm{~km}^{2}\right)$, the expected number of sites occupied by pairs of golden eagles in the sampling frame was $60(95 \% \mathrm{CI}=19-151)$, and the expected number of sites occupied by pairs within the focal sample of 175 sites surveyed was $27(95 \% \mathrm{CI}=9-67)$. In comparison, the observed (naïve) estimate of the total number of pairs detected at surveyed sites (i.e., sum of the maximum number of pairs detected per site) was 22 , or $18.5 \%$ lower than the modeled estimate.

\section{DISCUSSION}

We used a standardized sampling framework to identify relationships between landscape conditions and the presence of territorial pairs of golden eagles in an increasingly urbanized landscape. Our analysis and results showed that the presence of golden eagles in coastal southern California was most strongly associated with the spatial arrangement of remote and rugged terrain conditions, developed land cover, and to a lesser extent, scrubland vegetation cover. These findings were in general accordance with predicted habitat associations of golden eagles from previous studies of site occupancy that we used to guide model development (Wiens et al., 2018; Tack et al., 2020). Moreover, our findings echoed those from historical surveys (Dixon, 1937; Scott, 1985) and more recent telemetry studies of individually marked birds (Tracey et al., 2018a, 2020) that emphasized the sensitivity of golden eagles to expanding human development. Together, these previous studies and ours highlight the conservation value of remote, non-urbanized landscapes to remaining breeding pairs of golden eagles in coastal southern California. If resource managers and decision makers are interested in maintaining breeding pairs of golden eagles in the study region, our results indicate that the current strategy of maintaining open-space areas with minimal human interference is beneficial. Our results further demonstrated that site occupancy of golden eagles varied spatially in accordance with site-level landscape conditions. The randomized sampling design we used permitted us to not only identify existing relationships between site-level landscape conditions and the presence of eagle pairs, but also to project the spatial distribution of expected site-use by territorial pairs across sampled and unsampled areas of interest. This information provided regulatory officials and resource managers with (1) a map of specific landscape conditions and sites relevant to future conservation and monitoring activities for golden eagles; and (2) a strong baseline for assessing future changes in the sitelevel occurrence and status of territorial pairs of golden eagles in the study region.

The sampling design, field protocols, landscape covariates, and analytical approach we used replicated those used to investigate the site-occupancy dynamics in a large population of golden eagles in the northern Diablo Range and Altamont Pass Wind Resource Area of west-central California (Wiens et al., 2015, 2018). Estimates if density of territorial pairs of golden eagles in the Diablo Range are among the highest on record for this species worldwide (approximately 54 pairs per $1,000 \mathrm{~km}^{2}$; Wiens et al., 2015; Hunt et al., 2017; Katzner et al., 2020). Estimates of site occupancy for territorial pairs in the Diablo Range indicated that about $74 \%$ of the hexagon sampling grid was used by resident pairs of golden eagles during 2014 - 2018 (Wiens et al., 2018). In comparison to this robust northern population, our analyses in coastal southern California indicated that about $15 \%$ of the sampling grid was used by pairs of golden eagles. Underlying differences between the two study regions in terms of population stressors (e.g., urbanization) and availability of critical resources to eagles, such as prey, topography, wind conditions, and nesting substrates (e.g., rocky canyon cliffs vs. savannah oak woodlands), are most likely to explain the large difference we observed in patterns of occurrence. A strong and consistent finding in both study populations was a positive association between site occupancy by territorial pairs of eagles and rugged terrain conditions. Rugged terrain conditions are source contributors to orographic winds used by large, soaring birds of prey like golden eagles (Katzner et al., 2012; Fielding et al., 2020; Sur et al., 2020). 
The coarse-scale spatial covariates we used to represent landscape conditions likely missed many of the fine-scale features that influence occupancy and breeding success of golden eagles (for example, prey abundance), but the support for landscape covariates indicated that our analysis captured anticipated associations between landscape structure and expected occupancy by territorial pairs of eagles. Our analysis and results indicated that the probability of occupancy by eagles declined at sites with $>20 \%$ developed land cover (or $>2.8 \mathrm{~km}^{2}$ per territory-sized sample site). The study design predisposed us to have low power to detect relationships with developed areas, however, as sites with $>50 \%$ development were excluded from the sampling frame to facilitate our study objectives. Nonetheless, our findings paralleled those of recent telemetry studies in San Diego County showing that individual golden eagles avoided developed landscapes (Tracey et al., 2018a, 2020). Together these studies illustrate linkages between the behavioral mechanisms of resource selection and the occurrence and spatial distribution of sites used by breeding pairs of eagles. These results further indicate that territories currently used by golden eagles along the urban interface of coastal southern California are likely to be at the highest risk of extirpation as development increases. We estimated that the average rate at which sites became unoccupied between years of the study (local extinction; $\varepsilon$ ) was $17 \%$, whereas the rate at which sites became occupied between years (local colonization; $\gamma$ ) was essentially zero. We note, however, that the precision of estimated transition parameters was low. Additional years of monitoring would allow future analyses to accommodate possible sources of spatial variation in local extinction and colonization rates, thereby more fully capturing the site-level factors affecting the occupancy dynamics of golden eagles in our study region. Future analyses could also incorporate current or anticipated changes in landscape conditions, especially with regards to human land use and development, to identify how such conditions may interact with other, site-level population stressors (e.g., wildfire) to affect site-occupancy dynamics of golden eagles.

Our study emphasized the importance of accounting for imperfect and spatially variable detection rates in monitoring programs for golden eagles. The amount of forest cover at survey sites was an especially relevant factor affecting the detection of eagle pairs in our study. In contrast, detectability of territorial pairs of golden eagles in the northern Diablo Range declined within years over the course of the breeding season and varied little between years or with increasing amounts of forest cover at survey sites (Wiens et al., 2018, 2020). The capability to accommodate variable yet biologically relevant changes in detectability of eagles over space and time was a key benefit of our survey design and analytical approach. In our study, detectability of territorial pairs was approximately 50\% lower in the first year of surveys relative to the second, on average. We attributed a low detection probability in the first year of the study to: (1) a lack of familiarity and poor initial access to sites by field crews; and (2) a higher rate of nesting by territorial pairs in 2017, which may have facilitated detection of pairs in that year. Future monitoring efforts in the study region could improve detectability of pairs with more repeat surveys, or by integrating alternative field methods into the survey design, such as aerial or helicopter surveys of nest sites within sample sites (e.g., Watson et al., 2020). Many pairs of golden eagles are known to nest in steep, rocky canyons in our study area that could be surveyed more effectively with the integration of aerial approaches.

Breeding pairs of golden eagles were once regularly distributed throughout much of western San Diego County (Dixon, 1937; Scott, 1985). Historically, the primary form of habitat loss for golden eagles in southern California was farming, the diversion of water, and the conversion of native habitats into ranches and farmland (Hunter et al., 2003). More recent losses of both foraging and nesting areas of golden eagles have occurred in the form of residential (including golf courses) and commercial development, parks, wind farms, solar projects, military activity, mining operations, and an increasing frequency of wildfire (Tracey et al., 2018b; Syphard et al., 2019). Sprawling urbanization over the past 80 years, especially along coastal regions, is likely to have had a large impact on the historical distribution of golden eagles and led to an overall decline in numbers of breeding pairs. Although most urban development has occurred along coastal regions, development is increasingly moving eastward (Syphard et al., 2011, 2019). Based on observations of 27 pairs of golden eagles in northwestern San Diego County between 1900 and 1936, Dixon (1937) suggested $36 \mathrm{mi}^{2}\left(93 \mathrm{~km}^{2}\right)$ for the average home range size per pair. Scott (1985) resurveyed territories studied by Dixon (1937), in addition to areas of eastern San Diego County, and detected a total of 38 pairs of golden eagles during 1977 - 1981, or one pair per $88-150 \mathrm{~km}^{2}$ surveyed. Our modeled estimates indicated that the number of territory-sized sites used by pairs of eagles in the study region was approximately 60 , or one pair per $111 \mathrm{~km}^{2}$, which was within the range of historical observations. We note, however, that we sampled a larger area that included less developed and more remote landscapes of central San Diego, eastern Orange, and western Riverside counties relative to historical surveys.

\section{Applications for Monitoring and Conservation}

Mounting concerns about landscape and climate change, coupled with uncertainties regarding the response of golden eagles to conservation and management activities, highlight the importance of high-quality monitoring data that are applicable across multiple spatial and temporal scales. Our study used a probabilistic design based in the principles of sampling theory to identify the target population, sampling frame, and biologically appropriate sampling unit (Thompson et al., 1998; Wiens et al., 2015). Results from the design provided statistically robust and repeatable information on the presence and distribution of territorial golden eagles across multiple spatial scales while accounting for highly variable detection rates during surveys. Estimates of site occupancy provided here represent a valuable starting point for monitoring, rather than an absolute estimate of population status or size in the region. Nonetheless, the design easily accommodates dynamic modeling over multiple years to monitor and estimate population trends, changes in distribution (MacKenzie et al., 2006), or to identify sources of variation in 
other population parameters like nesting success (Wiens et al., 2015, 2018). Similar, random-plot based study designs have been shown to be effective for estimating broad-scale patterns in site occupancy for a variety of other wide-range terrestrial wildlife including barred owls (Strix varia; Wiens et al., 2011), large macaws (Ara spp.; Berkunsky et al., 2016), and wolverines (Gulo gulo; Lukacs et al., 2020). Results from these studies have allowed researchers and land managers to accurately define and map landscape attributes and environmental conditions that promote site-level occupancy and use, thereby highlighting specific areas for conservation and management.

Population responses of golden eagles to changes in human land use, landscape conditions, and climate are likely to be scaledependent, emphasizing the need to monitor their populations at multiple spatial scales. The sampling design and field protocols we used were well suited for monitoring golden eagles at a variety of spatial scales relevant to the management of golden eagles, ranging from individual territories (Kolar and Wiens, 2017) to clusters of territories within protected landscapes (Wiens et al., 2020) to broader regional populations exposed to multiple threats (Wiens et al., 2015, 2018). Our analysis and results highlighted the linkages between site-level landscape composition and distribution of territorial golden eagles at broad spatial scales. The spatial pattern we identified in the occurrence of golden eagles can serve as a useful prioritization metric for both monitoring and management efforts. We estimated the greatest site-level occupancy rates in the remote, nearly undeveloped portions of our sampling grid, including eastern and southern portions of San Diego County, the eastern portion of Orange County, and the southwestern portion Riverside County, suggesting these areas may have the greatest, most immediate conservation value for golden eagles in the study region. Because golden eagles are wide-ranging predators, targeted efforts to reduce human-caused disturbances to existing pairs and their nests can benefit broad-scale conservation of this species.

\section{DATA AVAILABILITY STATEMENT}

The data used for all analyses have been made available at ScienceBase under the following citation: Wiens et al. (2021).

\section{ETHICS STATEMENT}

Ethical review and approval was not required for the animal study because this research was conducted in compliance with the Guidelines to the Use of Wild Birds in Research.

\section{REFERENCES}

Bailey, L. L., Hines, J. E., Nichols, J. D., and MacKenzie, D. I. (2007). Sampling design trade-offs in occupancy studies with imperfect detection: examples and software. Ecol. Appl. 17, 281-290. doi: 10.1890/1051-0761(2007)017[0281: sdtios]2.0.co;2

Berkunsky, I., Cepeda, R. E., Marinelli, C., Simoy, M. V., Daniele, G., Kacoliris, F. P., et al. (2016). Occupancy and abundance

\section{AUTHOR CONTRIBUTIONS}

JW and PK conceived the research design. MM, JT, and PB led the data collection, entry, and verification. JW analyzed the data. All authors implemented the research and assisted with development of field methodology and writing and editing the manuscript.

\section{FUNDING}

This study was jointly funded by the California Department of Fish and Wildlife and the San Diego Association of Governments. The funding for publication fees provided by the U.S. Geological Survey.

\section{ACKNOWLEDGMENTS}

We thank Jeremy Sebes, Nicole Deatherage, Brennan Vettes, Peter Datema, Anna Fasoli, Karen Aerni, Nathan Gregory, Courtney Aiken, and the team at Western Riverside County Regional Conservation Authority for their field assistance. We thank Back Country Land Trust, Bureau of Land Management, California Department of Fish and Wildlife (CDFW), California State Parks, City of San Diego, Corte Madera Ranch, County of Riverside, County of San Diego, Irvine Ranch Conservancy, Marine Corps Air Station Miramar, Marine Corps Base Camp Pendleton, Orange County Parks, Orange County Water Authority, The Nature Conservancy, Pala Band of Mission Indians, Audubon Starr Ranch Sanctuary, Sweetwater Authority, U.S. Fish and Wildlife Service, U.S. Forest Service, U.S. Navy, Western Riverside County Regional Conservation Authority, Western Foundation of Vertebrate Zoology, and the many private landowners that provided permission to access their lands. Any use of trade, product, or firm names is for descriptive purposes only and does not imply endorsement by the U.S. Government. This publication has been peer reviewed and approved for publication consistent with USGS Fundamental Science Practices (http://pubs.usgs.gov/circ/1367/).

\section{SUPPLEMENTARY MATERIAL}

The Supplementary Material for this article can be found online at: https://www.frontiersin.org/articles/10.3389/fevo.2021. 665792/full\#supplementary-material

of large macaws in the Beni savannahs, Bolivia. Oryx 50, $113-120$.

Bibby, C. J., Burgess, N. D., Hill, D. A., and Mustoe, S. (2000). Bird Census Techniques. San Diego, CA: Academic Press.

Black, K. M., Preckler-Quisquater, S., Batter, T. J., Anderson, S., and Sacks, B. N. (2019). Occupancy, habitat, and abundance of the Sacramento Valley red fox. J. Wildl. Manag. 83, $158-166$. 
Bloom, P. H., Scott, J. M., Pattee, O. H., and Smith, M. R. (1989). "Lead contamination of golden eagles Aquila chrysaetos within the range of the California condor Gymnogyps californianus," in Proceedings of the International Conference on Birds of Prey-Raptors in the Modern World, Eilat, 481-482.

Brown, J. L. (2014). Desert Eagle Conservation Strategy. Report for the Department of Interior Region 8. Reno, NV: United States Fish and Wildlife Service.

Burnham, K. P., and Anderson, D. R. (2002). Model Selection and Multimodel Inference: A Practical Information-Theoretic Approach, 2nd Edn. New York,NY: Springer-Verlag.

Chandler, R. B., Royle, J. A., and King, D. I. (2011). Inference about density and temporary emigration in unmarked populations. Ecology 92, 1429-1435. doi: $10.1890 / 10-2433.1$

Clemesha, R. E. S., Gershunov, A., Iacobellis, S. F., Williams, A. P., and Cayan, D. R. (2016). The northward march of summer low cloudiness along the California coast. Geophys. Res. Lett. 43, 1287-1295.

Cooper, D. S., Yeh, P. J., and Blumstein, D. T. (2020). Tolerance and avoidance of urban cover in a southern California suburban raptor community over five decades. Urban Ecosyst. 24, 291-300. doi: 10.1007/s11252-020-01035-w

Dixon, J. B. (1937). The golden eagle in San Diego county, California. Condor 39, 49-56.

Crooks, K. R., and Soulé, M. E. (1999). Mesopredator release and avifaunal extinctions in a fragmented system. Nature 400, 563-566.

Dunk, J. R., Woodbridge, B., Lickfett, T. M., Bedrosian, G., Noon, B. R., LaPlante, D. W., et al. (2019). Modeling spatial variation in density of golden eagle nest sites in the western United States. PLoS One 14:e0223143. doi: 10.1371/journal. pone. 0223143

Evans, J. S., Oakleaf, J., Cushman, S. A., and Theobald, D. (2014). An ArcGIS Toolbox for Surface Gradient and Geomorphometric Modeling, Version 2.0.0.

Farley, K. A., Walsh, K., and Levine, A. S. (2017). Opportunities and obstacles for rangeland conservation in San Diego county, California, USA. Ecol. Soc. 22:38. doi: 10.5751/ES-09077-220138

Fielding, A. H., Haworth, P. F., Anderson, D., Benn, S., Dennis, R., Weston, E., et al. (2020). A simple topographical model to predict golden eagle Aquila chrysaetos space use during dispersal. Ibis 162, 400-415. doi: 10.1111/ibi.12718

Fiske, I., and Chandler, R. (2011). Unmarked: an R package for fitting hierarchical models of wildlife occurrence and abundance. J. Stat. Softw. 43, 1-23.

Gillespie, T. W., Pincetl, S., Brossard, S., Smith, J., Saatchi, S., Pataki, D., et al. (2012). A time series of urban forestry in Los Angeles. Urban Ecosyst. 15, 233-246. doi: 10.1007/s00267-009-9412-7

Grinnell, J. (1898). Birds of the Pacific Slope of Los Angeles County: A List of Brief Notes (No. 2). Pasadena, CA: Press of GA Swerdfiger.

Herring, G., Eagles-Smith, C. A., and Buck, J. (2017). Characterizing golden eagle risk to lead and anticoagulant rodenticide exposure: a review. J. Raptor Res. 51, 273-292.

Hewitt, J. E., Thrush, S. F., Dayton, P. K., and Bonsdorff, E. (2007). The effect of spatial and temporal heterogeneity on the design and analysis of empirical studies of scale-dependent systems. Am. Nat. 169, 398-408. doi: 10.1086/ 510925

Hole, D. G., Huntley, B., Arinaitwe, J., Butchart, S. H. M., Collingham, Y. C., Fishpool, L. D. C., et al. (2011). Toward a management framework for network of protected areas in the face of climate change. Conserv. Biol. 25, 305-315. doi: 10.1111/j.1523-1739.2010.01633.x

Hunt, W. G., Wiens, J. D., Law, P. R., Fuller, M. R., Hunt, T. L., Driscoll, D. E., et al. (2017). Quantifying the demographic cost of human-related mortality to a raptor population. PLoS One 12:e0172232. doi: 10.1371/journal.pone.017 2232

Hunter, R. D., Fisher, R. N., and Crooks, K. R. (2003). Landscape-level connectivity in coastal southern California, USA, as assessed through carnivore habitat suitability. Nat. Areas J. 23, 302-314.

Katzner, T. E., Brandes, D., Miller, T., Lanzone, M., Maisonneuve, C., Tremblay, J. A., et al. (2012). Topography drives migratory flight altitude of golden eagles: implications for on-shore wind energy development. J. Appl. Ecol. 49, 1178-1186.

Katzner, T. E., Kochert, M. N., Steenhof, K., McIntyre, C. L., Craig, E. H., and Miller, T. A. (2020). "Golden eagle (Aquila chrysaetos), version 2.0," in Birds of the World, eds P. G. Rodewald and B. K. Keeney (Ithaca, NY: Cornell Lab of Ornithology).
Katzner, T. E., Nelson, D. M., Braham, M. A., Doyle, J. M., Fernandez, N. B., Duerr, A. E., et al. (2017). Golden eagle fatalities and the continental-scale consequences of local wind-energy generation. Conserv. Biol. 31, 406-415. doi: 10.1111/cobi.12836

Kolar, P. S., and Wiens, J. D. (2017). Distribution, Nesting Activities, and AgeClass of Territorial Pairs of Golden Eagles at the Altamont Pass Wind Resource Area, California, 2014-16. U.S. Geological Survey Open-File Report 2017-1035. Reston, VA: U.S. Geological Survey, 18.

Lawler, J. J., Tear, T. H., Pyke, C., Shaw, M. R., Gonzalez, P., Kareiva, P., et al. (2008). Resource management in a changing and uncertain climate. Front. Ecol. Environ. 8, 35-43. doi: 10.1890/070146

Lesmeister, D. B., Davis, R. J., Singleton, P. H., and Wiens, J. D. (2018). "Northern spotted owl habitat and populations: status and threats," in Synthesis of Science to Inform Land Management Within the Northwest Forest Plan Area. Gen. Tech. Rep. PNW-GTR-966, Vol. 966, eds T. A. Spies, P. A. Stine, R. Gravenmier, J. W. Long, and M. J. Reilly (Portland, OR: US Department of Agriculture, Forest Service, Pacific Northwest Research Station), 245-299. doi: 10.1111/j. 1523-1739.2006.00387.x

Lovich, J. E. (2015). Golden eagle mortality at a utility-scale wind energy facility near Palm Springs, California. West. Birds 46, 76-80.

Lukacs, P. M., Evans Mack, D., Inman, R., Gude, J. A., Ivan, J. S., Lanka, R. P., et al. (2020). Wolverine occupancy, spatial distribution, and monitoring design. J. Wildl. Manag. 84, 841-851.

MacKenzie, D. I. (2005). What are the issues with presence-absence data for wildlife managers? J. Wildl. Manag. 69, 849-860.

MacKenzie, D. I., and Bailey, L. L. (2004). Assessing the fit of site occupancy models. J. Agric. Biol. Environ. Stat. 9, 300-318.

MacKenzie, D. I., Nichols, J. D., Hines, J. E., Knutson, M. G., and Franklin, A. B. (2003). Estimating site occupancy, colonization, and local extinction when a species is detected imperfectly. Ecology 84, 2200-2207. doi: 10.1890/091287.1

MacKenzie, D. I., Nichols, J. D., Royle, J. A., Pollock, K. H., Bailey, L. L., and Hines, J. E. (2006). Occupancy Estimation and Modeling: Inferring Patterns and Dynamics of Species Occurrence. San Diego, CA: Academic Press.

Martin, J., McIntyre, C. L., Hines, J. E., Nichols, J. D., Schmutz, J. A., and MacCluskie, M. C. (2009). Dynamic multistate site occupancy models to evaluate hypotheses relevant to conservation of golden eagles in Denali National Park, Alaska. Biol. Conserv. 142, 2726-2731.

Marzluff, J. M., Knick, S. T., Vekasy, M. S., Schueck, L. S., and Zarriello, T. J. (1997). Spatial use and habitat selection of golden eagles in southwestern Idaho. Auk $114,673-687$.

Mazerolle, M. J. (2020). AICcmodavg: Model Selection and Multimodel Inference Based on (Q)AIC(c). R Package Version 2.3-1. Available online at: https://cran.rproject.org/package=AICcmodavg (accessed February 20, 2020).

McClure, C. J., Westrip, J. R., Johnson, J. A., Schulwitz, S. E., Virani, M. Z., Davies, R., et al. (2018). State of the world's raptors: distributions, threats, and conservation recommendations. Biol. Conserv. 227, 390-402.

McLeod, D. R. A., Whitfield, D. P., and McGrady, M. J. (2002). Improving prediction of golden eagle (Aquila chrysaetos) ranging in western Scotland using GIS and terrain modeling. J. Raptor Res. 36, 70-77.

Millsap, B. A., Zimmerman, G. S., Sauer, S. R., Neilson, R. M., Otto, M., Bjerre, E., et al. (2013). Golden eagle population trends in the western United States: 1968-2010. J. Wildl. Manag. 77, 1436-1448.

Morin, D. J., Yackulic, C. B., Diffendorfer, J. E., Lesmeister, D. B., Nielsen, C. K., Reid, J., et al. (2020). Is your ad hoc model selection strategy affecting your multimodel inference? Ecosphere 11:e02997.

Nielson, R. M., Mcmanus, L., Rintz, T., Mcdonald, L. L., Murphy, R. K., Howe, W. H., et al. (2014). Monitoring abundance of golden eagles in the western United States. J. Wildl. Manag. 78, 721-730.

NOAA (2010). Coastal Change Analysis Program (C-CAP) Regional Land Cover Database. Charleston, SC, National Oceanic and Atmospheric Administration (NOAA) Coastal Services Center.

Pavlacky, D. C. Jr., Lukacs, P. M., Blakesley, J. A., Skorkowsky, R. C., Klute, D. S., Hahn, B. A., et al. (2017). A statistically rigorous sampling design to integrate avian monitoring and management within Bird Conservation Regions. PLoS One 12:e0185924. doi: 10.1371/journal.pone.018 5924 
R Core Team (2020). R: A Language and Environment for Statistical Computing. Vienna: R Foundation for Statistical Computing.

Reynolds, R. T., Graham, R. T., Reiser, M. H., Bassett, R. L., Kennedy, P. L., Boyce, S., et al. (1992). Management Recommendations for the Northern Goshawk in the Southwestern United States. RMRS-GTR-217. Fort Collins, CO: U.S. Department of Agriculture, Forest Service, Rocky Mountain Forest and Range Experiment Station.

Rich, L. N., Russell, R. E., Glenn, E. M., Mitchell, M. S., Gude, J. A., Podruzny, K. M., et al. (2013). Estimating occupancy and predicting numbers of gray wolf packs in Montana using hunter surveys. J. Wildl. Manag. 77, 1280-1289.

Riley, S. J., DeGloria, S. D., and Elliot, R. (1999). Index that quantifies topographic heterogeneity. Intermt. J. Sci. 5, 23-27.

Scott, T. A. (1985). Human Impacts on the Golden Eagle Population of San Diego County. MS thesis. San Diego, CA: San Diego State University.

Sergio, F., Newton, I. A. N., Marchesi, L., and Pedrini, P. (2006). Ecologically justified charisma: preservation of top predators delivers biodiversity conservation. J. Appl. Ecol. 43, 1049-1055.

Singh, N. J., Moss, E., Hipkiss, T., Ecke, F., Dettki, H., Sandström, P., et al. (2016). Habitat selection by adult golden eagles Aquila chrysaetos during the breeding season and implications for wind farm establishment. Bird Study 63, 233-240.

Spaul, R. J., and Heath, J. A. (2016). Nonmotorized recreation and motorized recreation in shrub-steppe habitats affects behavior and reproduction of golden eagles (Aquila chrysaetos). Ecol. Evol. 6, 8037-8049. doi: 10.1002/ece3.2540

Stahlecker, D. W., Wallace, Z. P., Mikesic, D. G., and Smith, C. S. (2017). Does Hopi religious harvest of eaglets affect golden eagle territory occupancy and reproduction on the Navajo Nation? J. Raptor Res. 51, 305-318.

Steenhof, K., Brown, J. L., and Kochert, M. N. (2014). Temporal and spatial changes in golden eagle reproduction in relation to increased off highway vehicle activity. Wildl. Soc. Bull. 38, 682-688.

Sur, M., Duerr, A. E., Bell, D. A., Fisher, R. N., Tracey, J. A., Bloom, P. H., et al. (2020). Relevance of individual and environmental drivers of movement of golden eagles. Ibis 162, 381-399.

Syphard, A. D., Brennan, T. J., and Keeley, J. E. (2019). Extent and drivers of vegetation type conversion in southern California chaparral. Ecosphere 10:e02796. doi: 10.1002/ajb2.1777

Syphard, A. D., Clarke, K. C., Franklin, J., Regan, H. M., and Mcginnis, M. (2011). Forecasts of habitat loss and fragmentation due to urban growth are sensitive to source of input data. J. Environ. Manag. 92, 1882-1893. doi: 10.1016/j.jenvman. 2011.03.014

Tack, J. D., Noon, B. R., Bowen, Z. H., and Fedy, B. C. (2020). Ecosystem processes, land cover, climate, and human settlement shape dynamic distributions for golden eagle across the western US. Anim. Conserv. 23, 72-82.

Thompson, W. L., White, G. C., and Gowan, C. (1998). Monitoring Vertebrate Populations. San Diego, CA: Academic Press.

Tracey, J. A., Madden, M. C., Bloom, P. H., and Fisher, R. N. (2020). A Clarification on the Effects of Urbanization on Golden Eagle (Aquila chrysaetos) Habitat Selection U.S. Geological Survey Open-File Report 2020-1110. Reston, VA: U.S. Geological Survey, 5.

Tracey, J. A., Madden, M. C., Bloom, P. H., Katzner, T. E., and Fisher, R. N. (2018a). Golden Eagle (Aquila chrysaetos) Habitat Selection as a Function of Land use and Terrain, San Diego County, California. U.S. Geological Survey Open-File Report 2018-1067. Reston, VA: U.S. Geological Survey, 13.

Tracey, J. A., Rochester, C. J., Hathaway, S. A., Preston, K. L., Syphard, A. D., Vandergast, A. G., et al. (2018b). Prioritizing conserved areas threatened by wildfire and fragmentation for monitoring and management. PLoS One 13:e0200203. doi: 10.1371/journal.pone.0200203
U. S. Fish and Wildlife Service [USFWS] (2016). Bald and Golden Eagles: Population Demographics and Estimation of Sustainable Take in the United States, 2016 Update. Washington, DC: U.S. Department of the Interior, Fish and Wildlife Service.

U. S. Geological Survey [USGS] (2015). The National Map, 3D Elevation Program Website. Available online at: http://nationalmap.gov/3dep_prodserv.html

Watson, J. W., Hayes, G. E., Keren, I. N., and Owens, T. E. (2020). Evidence for depressed reproduction of golden eagles in Washington. J. Wildl. Manag. 84, 1002-1011.

White, J. H., Smith, J. M., Bassett, S. D., Brown, J. L., and Ormsby, Z. E. (2018). Raptor nesting locations along an urban density gradient in the Great Basin, USA. Urban Ecosyst. 21, 51-60.

Whitfield, D. P., Fielding, A. H., McLeod, D. R. A., and Haworth, P. F. (2004). The effects of persecution on age of breeding and territory occupation in golden eagles in Scotland. Biol. Conserv. 118, 249-259.

Wiens, J. D., Anthony, R. G., and Forsman, E. D. (2011). Barred owl occupancy surveys within the range of the northern spotted owl. J. Wildl. Manag. 75, 531-538. doi: 10.1002/eap.1861

Wiens, J. D., Bloom, P. H., Madden, M. C., Kolar, P. S., Tracey, J. A., and Fisher, R. N. (2021). Detection/Non-Detection Data on Territorial Pairs of Golden Eagles in Coastal Southern California, 2016-2017: U.S. Geological Survey Data Release. Reston, VA: U.S. Geological Survey. doi: 10.5066/P9OIPLHH

Wiens, J. D., Kolar, P. S., and Bell, D. A. (2020). Distribution and Abundance of Aquila chrysaetos (Golden Eagle) in East Contra Costa County Habitat Conservation Plan/Natural Community Conservation Plan area, California. U.S. Geological Survey Open-File Report 2020-1107. Reston, VA: U.S. Geological Survey, 11. doi: 10.3133/ofr20201107

Wiens, J. D., Kolar, P. S., Fuller, M. R., Hunt, W. G., and Hunt, T. (2015). Estimation of occupancy, breeding success, and abundance of Golden Eagles (Aquila chrysaetos) in the Diablo Range, California, 2014. U.S. Geological Survey Open-File Report 2015-1039. Reston, VA: U.S. Geological Survey.

Wiens, J. D., Kolar, P. S., Hunt, W. G., Hunt, T., Fuller, M. R., and Bell, D. A. (2018). Spatial patterns in occupancy and reproduction of golden eagles during drought: prospects for conservation in changing environments. Condor 120, $106-124$.

Conflict of Interest: The authors declare that the research was conducted in the absence of any commercial or financial relationships that could be construed as a potential conflict of interest.

Publisher's Note: All claims expressed in this article are solely those of the authors and do not necessarily represent those of their affiliated organizations, or those of the publisher, the editors and the reviewers. Any product that may be evaluated in this article, or claim that may be made by its manufacturer, is not guaranteed or endorsed by the publisher.

Copyright (c) 2022 Wiens, Bloom, Madden, Kolar, Tracey and Fisher. This is an open-access article distributed under the terms of the Creative Commons Attribution License (CC BY). The use, distribution or reproduction in other forums is permitted, provided the original author(s) and the copyright owner(s) are credited and that the original publication in this journal is cited, in accordance with accepted academic practice. No use, distribution or reproduction is permitted which does not comply with these terms. 